\title{
The customer experience ecosystem in two cultural contexts
}

\author{
Mojtaba Barari $^{1} \cdot$ Olivier Furrer $^{2}$
}

Revised: 8 October 2018/Published online: 24 October 2018

(c) Springer Nature Limited 2018

\begin{abstract}
This study focuses on the development of a customer experience ecosystem during a journey which is embedded in meso- and macro-layers. Using the critical incident technique, the author collected in-depth interview data from bank customers in Switzerland and Iran to empirically study this ecosystem, including customercompany interaction in the micro-layer and social context of the meso-layer. Moreover, in a macro-layer analysis, the Hofstede cultural dimension was employed to show the role of cultural context in this ecosystem. The findings indicate that customer experience in the pre-encounter stage is mostly shaped by customer past experience and social context rather than company touchpoint. The importance of these factors is different in the two cultural contexts. Although customer experience in the encounter stage is mainly the result of customer and company interactions, other people have a role in this stage and cultural differences between the two countries largely explain these differences. Moreover, in the post-encounter stage, customers in different cultural contexts use various factors to evaluate their experiences and the effects on their emotional and behavioral responses. The findings provide key managerial implications for national and international
\end{abstract}

Mojtaba Barari

mojtaba.barari@griffithuni.edu.au

Olivier Furrer

olivier.furrer@unifr.ch

1 Department of Marketing, Griffith Business School, Griffith University, Gold Coast, QLD 4215, Australia

2 Department of Management, University of Fribourg, Bd de Pérolles 90, 1700 Fribourg, Switzerland companies with respect to the role of multiple layers in customer experience management.

Keywords Customer experience · Customer experience ecosystem - Service ecosystem · Customer journey · Cultural difference $\cdot$ Critical incident technique

\section{Introduction}

Increasingly, scholars believe that customer experience (CE) is the next competitive battleground for firms (Jain et al. 2017; Lemon and Verhoef 2016). CE has been defined as the internal and subjective customer response to any direct or indirect interaction with a company, its product, part of its organization, or contextual factors (Vargo and Akaka 2012) during the customer's purchase journey (Lemon and Verhoef 2016). While firms can rather easily imitate competitors' goods or services, replicating CE is more difficult because of CE's holistic nature (Hwang et al. 2016). By carefully managing interactions with customers, firms can gain and sustain a competitive advantage. In addition, firms obtain a better understanding of their customers' journey-from immediately before a customer's encounter with the firm until the end of the encounter (Homburg et al. 2015; Pine and Gilmore 1999)—which helps firms improve CE, enhance customer satisfaction and loyalty, and encourage customers to engage in positive word of mouth (Srivastava and Kaul 2016). Disney offers one of the best examples of CE management (Kuang 2016). The phrase "the Magic of Disney" expresses how the company co-creates unique experiences with customers and how, in turn, these experiences create mutual value, making Disney one of the most valuable brands in the world (Kuang 2016). 
Although much well-established work has examined CE (Homburg et al. 2015), its conceptualization, characterization, and frameworks are complicated and divergent (Homburg et al. 2015; Jain et al. 2017; Klaus et al. 2013). Because CE is a complex concept, researchers have used various approaches to capture it (Klaus et al. 2013). Recent research views $\mathrm{CE}$ as a process comprising a series of sequential activities that start before purchase and continue after purchase (Jain et al. 2017; Verhoef et al. 2009). In other words, $\mathrm{CE}$ is emerging during various phases of the customer journey (e.g., pre-, during, and post-encounter)a perspective that is congruent with the customer decisionmaking process (Voorhees et al. 2017) and is more in line with the comprehensive nature of CE (Jain et al. 2017) and the way most researchers see service consumption (Helkkula 2011).

Consumption experiences cannot be understood without considering the context in which they are made (Torres et al. 2014), and customers in different cultures evaluate the same experience differently (Torres et al. 2014). However, the role of cultural context during customer journey has received little attention (Lemon and Verhoef 2016) or has been limited to aspects such as service encounter evaluation (Guesalaga et al. 2016), service quality expectation (Donthu and Yoo 1998; Furrer et al. 2000), customer satisfaction (Torres et al. 2014), and loyalty (Seock and Lin 2011). CE researchers believe CE should be expanded from customer-company interaction (Lemon and Verhoef 2016) to encompass the role of contextual factors such as social environment (Carù and Cova 2015; Keiningham et al. 2017), cultural value, and economic and social context (Verhoef et al. 2009) to provide a more realistic picture of what is happening for customers (Lemon and Verhoef 2016). Our research question therefore is What is the role of different cultural contexts in CE formation through a journey from pre- to post-encounter?

This research takes a service ecosystem approach to consider context during the $\mathrm{CE}$ formation process. The service ecosystem perspective adopts a network-oriented view of value creation and tries to shift the focus from a dyadic exchange between company and customer to a broader context (De Keyser et al. 2015). This perspective posits that multiple actors across three layers-micro, meso, and macro-both influence and are influenced by customer-firm interaction and ultimately have an impact on the value creation process (Zhang et al. 2017). Thus, besides the micro-layer participants in customer-company interaction, meso-layer players such as suppliers, manufacturers, retailers, and other customers as well as macrolayer cultural, economic, and sociological factors are involved in the customer value creation process (Akaka et al. 2015). This perspective provides a richer and more dynamic conceptualization of service context than the traditional approach in service research (Akaka and Vargo 2015) and is used in the CE area to extend the dyadic customer-company interaction (De Keyser et al. 2015) because it provides a systematic view of the context of experience and could consider various factors that have an effect on CE through a journey (Akaka and Vargo 2015; Akaka et al. 2015). To better demonstrate the role of context on CE creation in the different layers, we rely on Switzerland and Iran as examples of different cultural contexts.

Our work is structured as follows. First, we present a summary of the theoretical review of CE and the customer journey, the service ecosystem, and the customer experience ecosystem. We then describe our research method, apply our framework for data analysis, and present our findings. Finally, we discuss conclusions, research limitations, and future lines of research.

\section{Literature review}

\section{Customer experience}

The CE literature originates with work on the symbolic, hedonic, and esthetic nature of consumption, providing an experiential view of consumption Holbrook and Hirschman (1982). Subsequently, research on experiential marketing focused on sensing, feeling, thinking, and acting and related aspects of consumption that create CE Schmitt (1999). However, the seminal book The Experience Economy Pine and Gilmore (1999) popularized the concept of CE, explaining that experiences constitute a distinct type of economic offerings from commodities, goods, and services.

Since this initial development, research in the CE area has been categorized into three streams reflecting the outcome, internal organization, and process perspectives Lemon and Verhoef (2016). The first research stream has focused mainly on the relationship between $\mathrm{CE}$ and its behavioral outcomes such as customer satisfaction, loyalty, and positive word of mouth (Garg et al. 2014; Srivastava and Kaul 2016; Zhang et al. 2017). These studies seek to understand how $\mathrm{CE}$ has an impact on these outcomes (Grewal et al. 2009; Verhoef et al. 2009) and the research attention is not on individual customers but on the aggregated experience of a group of respondents (Helkkula 2011).

The second research stream takes an internal approach in which the company tries to design and manage CE in regard to different stakeholders (Homburg et al. 2015). This approach adopts a mainly organizational view of $\mathrm{CE}$ and offers procedures and techniques to manage $\mathrm{CE}$. The third research stream takes a chronological process 
approach in which CE is formed during a journey based on the buying behavior process (Lemon and Verhoef 2016), extending from before the customer-company encounter to after the encounter's conclusion. From this perspective, customers go through several touch points: gathering of information, evaluating offerings, physical interactions, making purchases, consumption of services, and evaluation after consumption (Klaus et al. 2013). Importantly, these touch points may not necessarily belong to a company.

We apply a process-based model of CE because it covers the entire customer journey and provides an opportunity to consider the journey's context from a customer perspective. In contrast, the outcome-based view of CE focuses on post-service perception (Chang and Huang 2016), and the internal organization perspective of $\mathrm{CE}$ places attention on the design of the experience and considers company issues in CE management rather than customers.

\section{The customer journey}

The customer journey encompasses three stages (Klaus et al. 2013): pre-encounter, during the encounter, and postencounter. The pre-encounter stage starts when a customer recognizes a need and decides to satisfy it by purchasing a product or service (Lemon and Verhoef 2016; Voorhees et al. 2017). In the marketing literature, this stage includes need recognition, search, and consideration (Lemon and Verhoef 2016). The encounter stage encompasses customer involvement in the service delivery process and leads to product and service consumption (Lemon and Verhoef 2016; Voorhees et al. 2017). The vast majority of research in CE examines this stage (Tynan et al. 2014), in which the role of the company and its touch points such as products and services, employees, the servicescape, the service delivery process, promotion, and technology are vital for $\mathrm{CE}$ formation. The post-encounter experience starts after customer use of the products and services, when the customer assesses and acts on the experience in the two previous periods (Lemon and Verhoef 2016). Through this period, the firm's goal is to retain customers and to improve future service experiences (Hwang et al. 2016).

\section{The service ecosystem and service-dominant logic}

Service-dominant logic (SDL) has changed the foundations of traditional economic thought about exchange (Akaka et al. 2013). SDL claims that all exchange is service exchange and goods are service delivery tools (Akaka and Vargo 2015). From the SDL viewpoint, value is created during use, during which the customer and company jointly create the value (Grönroos and Voima 2013). Recently, SDL has developed the service ecosystem concept, expanding co-creation of value to include various actors who have a role in this process (Vargo and Lusch 2011). The service ecosystem focuses not only on multiple actors and their interaction but also on the importance of sociohistoric contexts, comprising multiple institutions that guide interactions and value determination through multiple layers (Akaka and Vargo 2015), with each layer nested within a broader layer (Chandler and Vargo 2011). In this ecosystem, the micro-layer includes dyadic interaction between the individual customer and the company, with each bringing resources and competencies to ultimately cocreate value through integration (Chandler and Vargo 2011). Exchange in the meso-layer is triadic, as a third party plays an intermediate role to serve the interests of two actors (Chandler and Vargo 2011). For instance, others could mediate the interaction between customer and company during service delivery and eventually have an impact on the co-creation experience. The context in the macrolayer of the service ecosystem includes an exchange between triads, creating a complex network of interactions that influence the entire value co-creation process (Chandler and Vargo 2011).

\section{Customer experience ecosystem framework}

The service ecosystem approach presents some issues with respect to its employment in the CE area. First, the focus of SDL and the service ecosystem is on the service provider or service system rather than the customer (Tynan et al. 2014). Thus, in this ecosystem, all possible social and economic actors (Vargo and Akaka 2012) in the value creation process are considered to provide a deep insight into how value is created in the market (Vargo and Lusch 2011) rather than attention being focused on value creation from the customer's perspective. Second, the sole focus of this ecosystem is interactions that relate directly to the service provider offering (Heinonen et al. 2010) during the service encounter stage. Consideration is not given to value creation in the absence of a service provider, especially in pre- and post-encounter customer-company interactions. To deal with these issues, we rely on the customer ecosystem concept, which offers a better fit with our conceptualization of CE. From this view, the customer orchestrates and dominates the value formation process (Tynan et al. 2014), in which the focus is limited to actors who have a more direct role in CE formation. In addition, the value creation process is not limited to the encounter stage (Melissa Archpru Akaka et al. 2015) but extends to include the impact of context on $\mathrm{CE}$ formation during a journey (Heinonen et al. 2013). Drawing on the customer journey and the customer ecosystem, we develop our CE ecosystem framework, which encompasses an entire journey from the pre-encounter stage through the encounter to 


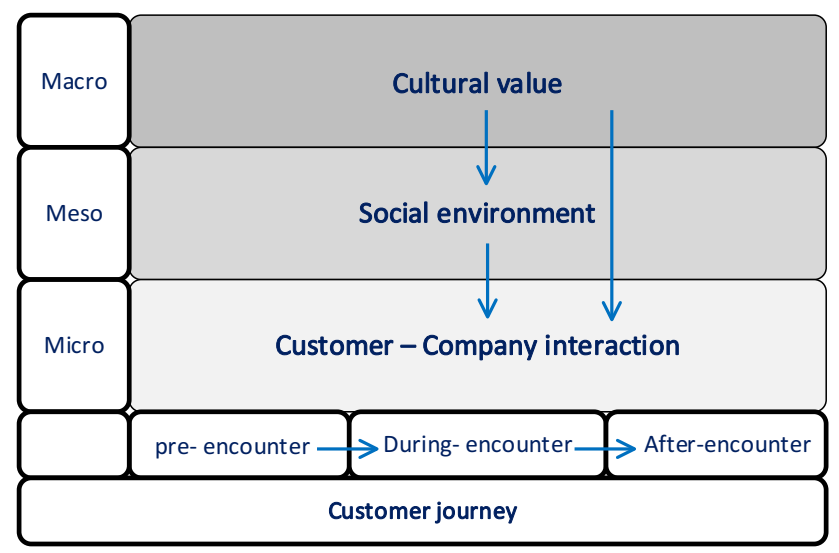

Fig. 1 Customer experience ecosystem

the post-encounter stage, with the stages taking place in three layers, as shown in Fig. 1.

In this framework, the micro-layer is focused on the dyadic interaction of the customer and the company, in which customers integrate their resources with service provider resources to co-create experience. Customers have specific needs and goals (Puccinelli et al. 2009), sociodemographic characteristics (Hwang et al. 2016), prior experience and knowledge (Hwang et al. 2016), and direct and indirect interaction with company touch points such as the company's marketing mix, which during a journey create an experience. These dyadic interactions are influenced by the meso-layer, in which the most influential factor is social environment (De Keyser et al. 2015), which includes other people both known and unknown to the customer.

Finally, the macro-layer includes variables such as economic, social, cultural, and sociological factors (Akaka et al. 2013) and acts as a stabilizing layer above the mesoand macro-layers (Chandler and Vargo 2011). Although all macro-factors are important, the most important and relevant factor in service marketing and $\mathrm{CE}$ is cultural values (Samuel Craig and Douglas 2006; Torres et al. 2014). To investigate the impact of cultural value within the macrolayer on the meso- and micro-layers, this study relies on Hofstede (1993) conceptualization. This perspective proposes five dimensions for cultural differences among countries. The first dimension is power distance, or "the extent to which the less powerful members of institutions and organizations within a country expect and accept that power is distributed unequally" (Hofstede et al. 1991). The second dimension, uncertainty avoidance, refers to the extent to which the members of a culture feel threatened by uncertain or unknown (Hofstede 1993), and the third dimension is individualism. In high-individualism cultures, people show greater levels of self-reliance, competitiveness, aggressive creativity, and insecurity, whereas in the opposite culture, collectivism, people are more concerned with the interests of their groups before their own (Hofstede and Hofstede 2001). Masculinity, the fourth dimension, appears as a dominant male sex role pattern in both traditional and modern societies: In countries with high masculine values, achievement and success are important, whereas in feminine countries caring for others and quality of life are important (Soares et al. 2007). The last dimension is the extent to which a society exhibits a long-term pragmatic, future-oriented perspective rather than a shortterm point of view (Hofstede et al. 1991).

\section{Research method}

The research question suggested the use of a qualitative method, because CE is a complex and multi-aspect phenomenon (Hwang et al. 2016) and a qualitative approach can provide a holistic understanding of this phenomenon (Harrison and Reilly 2011). We use the critical incident technique (CIT) to capture CE in the micro- and mesolayers during the customer journey. The CIT, which has been employed widely in service research (Greer 2015; Islam 2014), collects participants' narratives and self-reported stories as data and then applies content analysis to classify events, phenomena, or occurrences on the basis of identified incidents (Gremler 2004; Islam 2014).

This study was conducted in the banking industry because that industry is almost standard and homogenous around the world, especially in the retail section, with great similarity in the different aspect. This uniformity allows us to focus on the role of context instead of service offering differences. We draw on a convenience sample of 90 respondents, 45 from Switzerland and 45 from Iran, who were born and brought up in their countries, who had at least one banking experience during last 6 months, and who could remember the details of their experience from beginning to end. Data collection relied on semi-structured, in-depth interviews (Gremler 2004). In each interview, we asked participants to think about a positive or negative experience with their bank in the 6 months prior to the interview and then describe it from the beginning to after service consumption (Greer 2015) to cover all stages of the customer journey and role social context during the CE formation.

For data analysis, transcripts were first translated from French and Persian to English by a professional translator, after which we employed content analysis. We developed a codebook based on our research framework and related literature (Torres et al. 2014) to facilitate and guide our data analysis process (Tracy 2012), and modified the codebook during data analysis to include new themes as they emerged. For the analysis, the data were divided into 
the two cultural contexts for Iran and Switzerland and then the principal researcher, using content analysis, identified the experience component during the customer journey in micro- and meso-layers.

\section{Results and discussion}

Data analysis was conducted based on the customer experience ecosystem and results presented and discussed during the customer journey, from pre- to post-encounter in the micro-, meso-, and macro-layers.

\section{Pre-encounter stage}

In this stage, the customer gathers required information from different sources in order to choose an appropriate service provider. In a micro-layer, both the customer's past experience and information provided by a company play a role in $\mathrm{CE}$ formation in both countries. Findings indicate that, compared to company touchpoint, past experience has a more important role in $\mathrm{CE}$ formation, especially in Switzerland: "Bank spends a lot of money on advertising to tempt people while it is better you make your own decision...Gradually you get experience about different banking products and service and it helps me to choose the appropriate option." Past experience impacts on customer current experience because it shapes customer expectation and evaluation criteria (Akaka et al. 2015; Lemon and Verhoef 2016; Verhoef et al. 2009).

Moreover, data analysis shows that, in the meso-layer, highly regarded people (Carù and Cova 2015) consider it to be a very important source of information. Its impact is more obvious in Iran: "It is hard to trust bank advice because they consider their own benefit, my advice is to talk with people who have more experience in this area... I have some friends who are expert in this area."

Actually, in a high-risk purchase context, such as a bank, recommendations by trusted people are more important than information provided by the company (Garg et al. 2014; Tiong Tan and Chua 1986). Moreover, previous research in $\mathrm{CE}$ mainly considers the role of social context during customer and company interactions (Hwang et al. 2016; Verhoef et al. 2009), while the current findings indicate that the social context has an important role in $\mathrm{CE}$ during the pre-encounter stage and its impact is greater than company touchpoints in CE formation.

With regard to the macro-layer, in Iran, a collectivist culture, people tend to rely more on others' advice (Choi and Geistfeld 2004), even in personal and high-risk matters, such as financial matters (Devlin 2002), whereas in Switzerland, a more individualistic culture, financial decisions are more personal (Choi and Geistfeld 2004) and people tend to follow an independent decision-making style (Soares et al. 2007).

\section{The encounter stage}

This stage mainly includes customer interactions with company touch points, such as employees, products and services, technology, and the servicescape. As it is hard to trace the meso-layer's effect on customer interaction at different touchpoints, we consider the meso-layer as an overall factor that could have an impact on all customercompany interaction during the encounter while the role of the macro-layer is investigated at each touchpoint.

\section{Customer-employee interaction}

Data analysis indicates that customers consider different aspects when they have contact with a bank employee in the two countries, Switzerland and Iran. For people from Switzerland, employee capability was important in their experience: "Although it was a very young man it was very professional and responses to all my questions quickly... some employees tell all the time, let me check, let me check."

In Iran, however, people consider the social aspects of an employee in their experience and they prefer to receive service in a warm and respectful manner: "I usually go to some specific branches because their employee knows me, and they are very respectful... apart from work, it is important to have warm chat with an employee, otherwise what is the difference between a person and ATM."

Previous research in CE indicates that the employee is a major antecedent of positive and negative $\mathrm{CE}$ creation (Hwang et al. 2016; Voorhees et al. 2017), while the current research findings indicate that a customer from a different cultural context has a different expectation of their encounter with an employee. In this regards, Akaka et al. (2013) indicate that the phenomenon of employees smiling to customers does not result in positive experiences in all cultural contexts because in some cultures this is regarded as inappropriate behavior.

From the macro-layer, in high masculinity cultures such as Switzerland, people have a more functional orientation (Blut et al. 2015), so employee performance and abilities are more vital than the social relationship in their service experience (Furrer et al. 2000). In Iran, however, which comprises a low masculinity and collectivist culture, customers consider the quality of interpersonal relations with employees to be an important factor in their quality of experience (Torres et al. 2014). 


\section{Customer-technology interaction}

Technology plays a role in CE formation in Iran and Switzerland. In both countries, customers mostly mention the functional aspect of technology rather than the experiential aspect of their technology experience. In contrast to industries such as retailing, in which both hedonic and utilitarian aspects of technology play a role in CE, utilitarian experience has greater weight in the bank industry (Roy 2018). Moreover, this impact is more obvious in Iran: "Technology facilitates my banking works... when you use technology it does not need to wait, fill a lot of paper and ask an employee to do a favor for a very simple transaction."

In addition to functionality of technology, people in Switzerland consider security as another important factor in their technology experience: "Although banking technology is very helpful, you should care, a simple mistake could lead to losing the whole your money... I know some people save all their banking password in their mobile, how dare they!". In this regard, previous research in CE indicates that technology is becoming an integral part of $\mathrm{CE}$ (Verhoef et al. 2009) because it empowers customers (Stein and Ramaseshan 2016) and increases the quality of their experience (Lemon and Verhoef 2016).

From the macro-layer, in Iran banks have power over customers (Furrer et al. 2000) so that technology provides a way to facilitate customer needs and satisfaction, whereas in Switzerland people do not face this situation. However, in Switzerland, with its individualistic culture, privacy and security play an important role in interaction with technology (Choi and Geistfeld 2004).

\section{Customer-servicescape interaction}

The findings indicate that the servicescape has an impact on CE formation in both countries, especially in Switzerland. Moreover, in this country, the customer is more focused on tangible aspect of servicescapes, such as layout and functionality: "I always like this branch...they are modern and well-designed... everything is in the right places."

In Iran, the customer tends to consider the more shambolic aspect of servicescape: "In some branches, they devote a lot of space to the employee behind the counter while there is not enough space for customer... It is disrespectful to the customer."

Previous research in $\mathrm{CE}$ indicates that servicescapes have great impact on CE formation because they impact customer perception and then behavior (Puccinelli et al. 2009; Stein and Ramaseshan 2016) The current research findings, however, indicate that people from different cultures consider various aspects of their service settings.
With respect to the macro-layer, people from a masculine culture, such as Switzerland, consider the more functional aspect of the servicescape, whereas customers from Iran, a more feminine culture, consider experiential aspects of the servicescape (Blut et al. 2015).

This interpretation holds true from the individualistic perspective in which people are more object-oriented than in collectivistic cultures, which are subjectively oriented (Sharma et al. 2016). Thus, customers in Switzerland seek tangible cues rather than intangible aspects of the environment in their CE (Mattila 1999).

\section{Customer-product interaction}

Analysis indicates that although products and services are an integral part of CE formation in Iran and Switzerland, people in each country consider different aspects of them in their experience. Iranian customers consider the quality of service delivery as the important factor in their experience formation: "I know, all banks products and services are the same but I prefer private banks because at least they answer your question properly and try to facilitate your work."

In Switzerland, however, the quality of core product and services has the important role in their experience: "I have been working with this bank several years and during these years I saw good and bad employees....apart from people it is important to get what do you want."

Company products and services are considered a most important touchpoint (Grewal et al. 2009) in CE management (Hwang et al. 2016); however, aspects of products and services vary from one context to another. In the macro-layer, Iranian customers do not have enough power to negotiate the service offering (Furrer et al. 2000), so they only expect to receive service in a better manner. In contrast, in Switzerland, with its individualistic culture, customers are functionally oriented and place more emphasis on the offering itself (Singh 2006).

\section{Meso-layer}

This layer is considered during the encounter stage because it can influence customer interaction with company touch points. From customers' responses, two aspects emerged as important during the encounter: accompanying known people and the presence of unknown people. In Iran more than Switzerland, the customer tends to go with known people, such as family or friends, to the bank: "Although it is not possible to go bank with a companion I always prefer to going with somebody... I do not know why but it makes me more comfortable and if there anything I could get him/ her advice."

It seems Iranians, in a collectivist culture, are more susceptible to others' opinions, which help them arrive at a 
more acceptable decision, while in Switzerland, an individualistic culture, people are more independent and are more comfortable with self-decision-making (Kim et al. 2016)

Moreover, the presence of others in settings such as amusement parks or retail sections may have positive effects on CE (Terblanche 2018). In a bank, however, crowding or increased waiting time (Garg et al. 2014) can generate unpleasant feelings because they decrease customers' control over their surroundings and interrupt their privacy (Chang and Huang 2016). Although this factor affects CE in both countries, it is more important for Swiss customers because in Switzerland customers are more concerned about their privacy and do not like crowded settings (Triandis 1995).

\section{Post-encounter stage}

This stage includes customers' emotional and behavioral responses to their experience before and during the encounter, which determine their satisfaction, loyalty, and word of mouth.

\section{Satisfaction and loyalty}

Data analysis indicates that customers consider different factors when evaluating their experience. Iranian CE evaluation is based more on the bank employee's treatment and needs fulfillment. In other words, customers in Iran are more concerned with satisfying their needs through the appropriate behavior of employees: "Usually it is hard to have high expectations from an Iranian bank, all are the same...I wait for a long time to ask a question about a problem about my credit card but the employee behavior was very unpolite and cold...I thinking to work with another bank."

In Switzerland, however, product and service quality is considered to be the main measure for a customer to evaluate their experience: "I could not tolerate low service quality and will complain about it immediately... I'll put all my money in this bank and they get a huge amount of fees so I deserve high-quality services." The findings indicate that people from different contexts use various factors to evaluate their experiences and this leads to different emotional and behavioral responses.

From a macro-layer perspective, in Switzerland, with high individualism, people are self-responsible and expect high-quality service and are less tolerant of poor service quality (Zhang et al. 2008). In the collectivistic culture of Iran, customers put more emphasis on the quality of their treatment by an employee (Tiong Tan and Chua 1986). With respect to the power distance dimension, banks could be considered as a powerful organization in a culture with high power distance, such as in Iran, so customers form low service quality expectations and are more concerned about need fulfillment itself than about how the need is satisfied (Kueh and Ho Voon 2007).

\section{Word of mouth}

In both countries, people tend to share their experiences with people who they know, especially in Iran: "I had a lot of negative experience in my banking interaction...I warn my friends about this...there is the difference between bank ads and reality...they do not tell the whole of the story." Previous research indicates that word of mouth is the common way for customers to share their positive or negative experiences with other people (Bagdare and Jain 2013; Klaus et al. 2013).

From the macro-layer, in a collectivist country such as Iran, customers have greater access to social channels compared to Switzerland for engaging in word of mouth, even with people they may not know well (Liu et al. 2001). In contrast, in Switzerland, an individualistic culture, word of mouth is limited to the immediate social circle (Zhang et al. 2008). In addition, Iranian customers do not have power over service provider offerings, so dissatisfied customers use word of mouth as a coping strategy (Yi and Baumgartner 2004).

\section{Theoretical implication}

Recent models in CE embrace the customer journey in the concept to expand the role of company touchpoints in $\mathrm{CE}$ formation, from the beginning to after the encounter (Lemon and Verhoef 2016; Stein and Ramaseshan 2016; Voorhees et al. 2017). These models, however, pay less attention to context and focus mainly on customer and company interaction. To provide more comprehensive and dynamic views of $\mathrm{CE}$, this research takes the customer ecosystem model to extend the CE concept from microlayer (customer and company interaction) to include the meso-layer (social context) and macro-layer (cultural context). In contrast to the service ecosystem, which considers all stakeholders and the interactions between them to describe value creation in the market (Akaka and Vargo 2015; Akaka et al. 2013), the customer is placed in the center of the ecosystem and to show how customer and company interaction is influenced by the meso- and macrolayers during a journey to describe the $\mathrm{CE}$ formation process. Moreover, the empirical findings support this ecosystem and indicate an interaction between the social context of the meso-layer and cultural values of the macrolayer to explain how people from different contexts differ in their CE. For instance, the same touchpoint, such as the 
servicescape, has a different role in $\mathrm{CE}$ in different social and cultural contexts. In addition, the service ecosystem describes the value creation process during customer and company encounters (Akaka and Vargo 2015; Akaka et al. 2015), while with respect to CE management, the before and after encounter stage is very important in attracting and retaining customers (Lemon and Verhoef 2016). So, the customer ecosystem not only extends this process to before and after the encounter, but also considers the role of social and cultural contexts during the whole customer journey.

Finally, the study of the role of social (Bitner 1992; Miao et al. 2011; Rosenbaum and Massiah 2011) and cultural context (Donthu and Yoo 1998; Guesalaga et al. 2016; Mattila 1999) in service experience is not a new topic. However, the $\mathrm{CE}$ ecosystem situates previous research in service marketing within an ecosystem and it enables us to not only consider customer and company interaction in the micro-layer with a broader context in the meso- and macro-layers but also considers the interactions between these layers to provide a more systematic and dynamic view of CE formation.

\section{Practical implications}

CE management is necessary for all companies, especially for international companies, such as banks, who have branches in various countries because it will help them to succeed in the marketplace. This is not an easy task, and previous research indicates that to overcome this issue, a company should use techniques, such as customer journey mapping, to get a view of different touchpoints and their impact on CE formation (Lemon and Verhoef 2016; Stein and Ramaseshan 2016). The research findings show that when we consider experience formation from a customer ecosystem view it is more complicated and dynamic since experiences in the micro-layer are embedded in the mesoand macro-layers. Hence, international companies should develop an ecosystem view of CE to gain insight into how interactions between their touchpoints with the social context in the meso-layer and the cultural context in the meso-layer lead to CE during a journey. Moreover, an ecosystem view of experience is not only important for an international company (Akaka et al. 2013), it also helps national companies to understand the importance of context in CE formation. CE is always individual and unique for each customer in his/her consumption journey (Akaka et al. 2013; Lemon and Verhoef 2016) because each experience goes through a journey and is the result of interaction between different layers. So, viewing the experience from an ecosystem perspective helps companies to acquire a more realistic view of $\mathrm{CE}$ and, like Disney, turn this challenge into a competitive advantage.

\section{Limitations and future research}

This study, like others, has some limitations, most of which originated from the methodology. Using the critical incident technique, we asked customers to tell their story and our data analysis was based on this story. Customers related their experiences months after it happened, and they may not have remembered all the details of their experience. In addition, owing to the small sample size, the outcome cannot be generalized to a whole population or other industries, and caution is in order in using the research results. In contrast to other industries, the banking industry is very similar in different countries in terms of products and services and the service delivery process. For example, financial issues are very private, which influences the whole customer journey from need recognition to the source of information and the role of the social environment. In this regard, future research should examine CE in different industries to get a better view of the role of culture in CE formation. Finally, as CE is usually viewed only from a customer perspective, future research could investigate $\mathrm{CE}$ from the customer and company perspectives at the same time to provide a broader and more realistic picture of CE.

\section{References}

Akaka, M.A., and S.L. Vargo. 2015. Extending the context of service: From encounters to ecosystems. Journal of Services Marketing 29(6/7): 453-462.

Akaka, M.A., S.L. Vargo, and R.F. Lusch. 2013. The complexity of context: A service ecosystems approach for international marketing. Journal of International Marketing 21(4): 1-20.

Akaka, M.A., S.L. Vargo, and H.J. Schau. 2015. The context of experience. Journal of Service Management 26(2): 206-223.

Bagdare, S., and R. Jain. 2013. Measuring retail customer experience. International Journal of Retail \& Distribution Management 41(10): 790-804.

Bitner, M.J. 1992. Servicescapes: The impact of physical surroundings on customers and employees. The Journal of Marketing 56: $57-71$.

Blut, M., N. Chowdhry, V. Mittal, and C. Brock. 2015. E-service quality: A meta-analytic review. Journal of Retailing 91(4): 679-700.

Carù, A., and B. Cova. 2015. Co-creating the collective service experience. Journal of Service Management 26(2): 276-294. https://doi.org/10.1108/josm-07-2014-0170.

Chandler, J.D., and S.L. Vargo. 2011. Contextualization and value-incontext: How context frames exchange. Marketing Theory 11(1): $35-49$.

Chang, W.-L., and L.-Y. Huang. 2016. Measuring service experience: A utility-based heuristic model. Service Business 10(1): 1-30.

Choi, J., and L.V. Geistfeld. 2004. A cross-cultural investigation of consumer e-shopping adoption. Journal of Economic Psychology 25(6): 821-838.

De Keyser, A., K.N. Lemon, P. Klaus, and T.L. Keiningham. 2015. A framework for understanding and managing the customer 
experience. Marketing science institute working paper series, pp. $15-121$.

Devlin, J.F. 2002. Customer knowledge and choice criteria in retail banking. Journal of Strategic Marketing 10(4): 273-290.

Donthu, N., and B. Yoo. 1998. Cultural influences on service quality expectations. Journal of Service Research 1(2): 178-186.

Furrer, O., B.S.-C. Liu, and D. Sudharshan. 2000. The relationships between culture and service quality perceptions basis for crosscultural market segmentation and resource allocation. Journal of Service Research 2(4): 355-371.

Garg, R., Z. Rahman, and M. Qureshi. 2014. Measuring customer experience in banks: Scale development and validation. Journal of Modelling in Management 9(1): 87-117.

Greer, D.A. 2015. Defective co-creation: Developing a typology of consumer dysfunction in professional services. European Journal of Marketing 49(1/2): 238-261.

Gremler, D.D. 2004. The critical incident technique in service research. Journal of Service Research 7(1): 65-89.

Grewal, D., M. Levy, and V. Kumar. 2009. Customer experience management in retailing: An organizing framework. Journal of Retailing 85(1): 1-14.

Grönroos, C., and P. Voima. 2013. Critical service logic: Making sense of value creation and co-creation. Journal of the Academy of Marketing Science 41(2): 133-150.

Guesalaga, R., M. Pierce, and D. Scaraboto. 2016. Cultural influences on expectations and evaluations of service quality in emerging markets. International Marketing Review 33(1): 88-111.

Harrison, R.L., and T.M. Reilly. 2011. Mixed methods designs in marketing research. Qualitative Market Research: An International Journal 14(1): 7-26.

Heinonen, K., T. Strandvik, K.-J. Mickelsson, B. Edvardsson, E. Sundström, and P. Andersson. 2010. A customer-dominant logic of service. Journal of Service Management 21(4): 531-548.

Heinonen, K., T. Strandvik, and P. Voima. 2013. Customer dominant value formation in service. European Business Review 25(2): 104-123.

Helkkula, A. 2011. Characterising the concept of service experience. Journal of Service Management 22(3): 367-389.

Hofstede, G. 1993. Cultural constraints in management theories. The Academy of Management Executive 7(1): 81-94.

Hofstede, G., G.J. Hofstede, and M. Minkov. 1991. Cultures and organizations: Software of the mind. New York: McGraw-Hill.

Hofstede, G.H., and G. Hofstede. 2001. Culture's consequences: Comparing values, behaviors, institutions and organizations across nations. Thousand Oaks: Sage.

Holbrook, M.B., and E.C. Hirschman. 1982. The experiential aspects of consumption: Consumer fantasies, feelings, and fun. Journal of Consumer Research 9(2): 132-140.

Homburg, C., D. Jozić, and C. Kuehnl. 2015. Customer experience management: Toward implementing an evolving marketing concept. Journal of the Academy of Marketing Science 45: 1-25.

Hwang, J., J. Hwang, S. Seo, and S. Seo. 2016. A critical review of research on customer experience management: Theoretical, methodological and cultural perspectives. International Journal of Contemporary Hospitality Management 28(10): 2218-2246.

Islam, A.N. 2014. Sources of satisfaction and dissatisfaction with a learning management system in post-adoption stage: A critical incident technique approach. Computers in Human Behavior 30: 249-261.

Jain, R., R. Jain, J. Aagja, J. Aagja, S. Bagdare, and S. Bagdare. 2017. Customer experience-A review and research agenda. Journal of Service Theory and Practice 27(3): 642-662.

Keiningham, T., T. Keiningham, J. Ball, J. Ball, S. Benoit, S. Benoit, and A. Buoye. 2017. The interplay of customer experience and commitment. Journal of Services Marketing 31(2): 148-160.
Kim, S., S. Kim, J.-E. Chung, J.-E. Chung, Y. Suh, and Y. Suh. 2016. Multiple reference effects on restaurant evaluations: A crosscultural study. International Journal of Contemporary Hospitality Management 28(7): 1441-1466.

Klaus, P., M. Gorgoglione, D. Buonamassa, U. Panniello, and B. Nguyen. 2013. Are you providing the "right" customer experience? The case of Banca Popolare di Bari. International Journal of Bank Marketing 31(7): 506-528.

Kuang, C. 2016. Disney's \$1 Billion bet on a magical wristband. WIRED.

Kueh, K., and B. Ho Voon. 2007. Culture and service quality expectations: Evidence from Generation $\mathrm{Y}$ consumers in Malaysia. Managing Service Quality: An International Journal 17(6): 656-680.

Lemon, K.N., and P.C. Verhoef. 2016. Understanding customer experience throughout the customer journey. Journal of Marketing 80(6): 69-96. https://doi.org/10.1509/jm.15.0420.

Liu, B.S.-C., O. Furrer, and D. Sudharshan. 2001. The relationships between culture and behavioral intentions toward services. Journal of Service Research 4(2): 118-129.

Mattila, A.S. 1999. The role of culture and purchase motivation in service encounter evaluations. Journal of Services Marketing 13(4/5): 376-389.

Miao, L., A.S. Mattila, and D. Mount. 2011. Other consumers in service encounters: A script theoretical perspective. International Journal of Hospitality Management 30(4): 933-941.

Pine, B., and J. Gilmore. 1999. The experience economy. Boston: Harvard Business School Press.

Puccinelli, N.M., R.C. Goodstein, D. Grewal, R. Price, P. Raghubir, and D. Stewart. 2009. Customer experience management in retailing: Understanding the buying process. Journal of Retailing 85(1): $15-30$.

Rosenbaum, M.S., and C. Massiah. 2011. An expanded servicescape perspective. Journal of Service Management 22(4): 471-490.

Roy, S. 2018. Effects of customer experience across service types, customer types and time. Journal of Services Marketing 80: 69-96.

Samuel Craig, C., and S.P. Douglas. 2006. Beyond national culture: Implications of cultural dynamics for consumer research. International Marketing Review 23(3): 322-342.

Schmitt, B.H. 1999. Experiential marketing: How to get customers to sense, feel, think, act and relate to your company and brand. New York: Free Press.

Seock, Y.-K., and C. Lin. 2011. Cultural influence on loyalty tendency and evaluation of retail store attributes: An analysis of Taiwanese and American consumers. International Journal of Retail \& Distribution Management 39(2): 94-113.

Sharma, P., P. Sharma, Z. Wu, Z. Wu, Y. Su, and Y. Su. 2016. Role of personal cultural orientations in intercultural service encounters. Journal of Services Marketing 30(2): 223-237.

Singh, S. 2006. Cultural differences in, and influences on, consumers' propensity to adopt innovations. International Marketing Review 23(2): 173-191.

Soares, A.M., M. Farhangmehr, and A. Shoham. 2007. Hofstede's dimensions of culture in international marketing studies. Journal of Business Research 60(3): 277-284.

Srivastava, M., and D. Kaul. 2016. Exploring the link between customer experience-loyalty-consumer spend. Journal of Retailing and Consumer Services 31: 277-286.

Stein, A., and B. Ramaseshan. 2016. Towards the identification of customer experience touch point elements. Journal of Retailing and Consumer Services 30: 8-19. https://doi.org/10.1016/j. jretconser.2015.12.001.

Terblanche, N.S. 2018. Revisiting the supermarket in-store customer shopping experience. Journal of Retailing and Consumer Services 40: 48-59. 
Tiong Tan, C., and C. Chua. 1986. Intention, attitude and social influence in bank selection: A study in an oriental culture. International Journal of Bank Marketing 4(3): 43-53.

Torres, E.N., X. Fu, and X. Lehto. 2014. Examining key drivers of customer delight in a hotel experience: A cross-cultural perspective. International Journal of Hospitality Management 36: $255-262$.

Tracy, S.J. 2012. Qualitative research methods: Collecting evidence, crafting analysis, communicating impact. New York: Wiley.

Triandis, H.C. 1995. Individualism and collectivism. Boulder, CO: Westview Press.

Tynan, C., S. McKechnie, and S. Hartley. 2014. Interpreting value in the customer service experience using customer-dominant logic. Journal of Marketing Management 30(9-10): 1058-1081.

Vargo, S.L., and M.A. Akaka. 2012. Value cocreation and service systems (re) formation: A service ecosystems view. Service Science 4(3): 207-217.

Vargo, S.L., and R.F. Lusch. 2011. It's all B2B... and beyond: Toward a systems perspective of the market. Industrial Marketing Management 40(2): 181-187.

Verhoef, P.C., K.N. Lemon, A. Parasuraman, A. Roggeveen, M. Tsiros, and L.A. Schlesinger. 2009. Customer experience creation: Determinants, dynamics and management strategies. Journal of Retailing 85(1): 31-41.

Voorhees, C.M., P.W. Fombelle, Y. Gregoire, S. Bone, A. Gustafsson, R. Sousa, and T. Walkowiak. 2017. Service encounters, experiences and the customer journey: Defining the field and a call to expand our lens. Journal of Business Research 79: 269-280.

Yi, S., and H. Baumgartner. 2004. Coping with negative emotions in purchase-related situations. Journal of Consumer Psychology 14(3): 303-317.
Zhang, J., S.E. Beatty, and G. Walsh. 2008. Review and future directions of cross-cultural consumer services research. Journal of Business Research 61(3): 211-224.

Zhang, M., M. Hu, L. Guo, and W. Liu. 2017. Understanding relationships among customer experience, engagement, and word-of-mouth intention on online brand communities: The perspective of service ecosystem. Internet Research 27: 839-857.

Mojtaba Barari is marketing student at the Griffith University in Gold Coast, Australia. His research mainly focuses on service marketing and especially customer experience, customer experience management, and cross-cultural study.

Olivier Furrer is Chaired Professor of Marketing at the University of Fribourg in Switzerland and Visiting Lecturer at the University of Geneva (Switzerland) and the University of Lille (France). Previously, he held positions at the Radboud University Nijmegen (The Netherlands), the University of Birmingham (UK), and the University of Illinois at Urbana-Champaign (USA). He holds a Ph.D. from the University of Neuchâtel (Switzerland). His main research interests are in the areas of cross-cultural and strategic marketing management. He has published research articles in such journals as Journal of International Business Studies, Management International Review, Journal of International Management, and Journal of Business Ethics, among others. He recently wrote the second edition book titled Corporate Level Strategy: Theory and Applications published by Routledge. 